Case Report

\title{
A Unique Case of Malignant Pleuropericardial Effusion: HHV-8-Unrelated PEL-Like Lymphoma-A Case Report and Review of the Literature
}

\author{
Farhan Mohammad, ${ }^{1}$ Muhammad Neaman Siddique, ${ }^{2}$ Faraz Siddiqui, ${ }^{1}$ M. Popalzai, ${ }^{2}$ \\ Masoud Asgari, ${ }^{3}$ and Marcel Odaimi ${ }^{2}$ \\ ${ }^{1}$ Department of Internal Medicine, Staten Island University Hospital, Staten Island, NY 10305, USA \\ ${ }^{2}$ Department of Hematology-Oncology, Staten Island University Hospital, Staten Island, NY 10305, USA \\ ${ }^{3}$ Department of Pathology and Laboratory Medicine, Staten Island University Hospital, Staten Island, NY 10305, USA
}

Correspondence should be addressed to Farhan Mohammad; drfarhan4u@gmail.com

Received 15 December 2013; Accepted 18 January 2014; Published 4 March 2014

Academic Editors: C. Gennatas and J. M. Ribera

Copyright (C) 2014 Farhan Mohammad et al. This is an open access article distributed under the Creative Commons Attribution License, which permits unrestricted use, distribution, and reproduction in any medium, provided the original work is properly cited.

\begin{abstract}
Primary effusion lymphoma (PEL) or body cavity lymphoma is a rare type of extra nodal lymphoma of B-cell origin that presents as lymphomatous effusion(s) without any nodal enlargement or tumor masses. It belongs to the group of AIDS related non-Hodgkin's lymphomas. First described in 1996 in HIV infected individuals who were coinfected with Kaposi's sarcoma-associated herpesvirus (KSHV) or HHV-8 virus, it was included as a separate entity in WHO classification of tumors of hematopoietic and lymphoid tissue in the year 2001. The definition included association with HHV-8 virus as a mandatory diagnostic criterion. However, cases were later reported where PEL-like disease process was diagnosed in HHV-8 negative patients. This was eventually recognized as a rare but distinct entity termed as "HHV-8-unrelated PEL-like lymphoma". Herein, we are reporting a case of an elderly patient who presented with a large pleuropericardial effusion and was eventually diagnosed with this entity. Till date, only around 50 cases of HHV-8-unrelated PEL-like lymphoma have been reported and our case being EBV, HIV, and Hepatitis C negative makes it very unique and rare occurrence. We are also presenting a review of relevant literature focused mainly on comparing outcomes in patients treated with and without chemotherapy.
\end{abstract}

\section{Case Presentation}

A 76-year-old ex-smoker male with past medical history of hypertension and atrial fibrillation presented with exertional dyspnea and a recent weight loss of $15 \mathrm{lbs}$. He denied substance abuse. Review of systems and EKG were negative. On physical examination, breath sounds at bilateral lung bases were decreased. The superficial lymph nodes, liver, and spleen were not palpable on physical examination. There was no lower extremity edema. Hemogram revealed a WBC count of 10,700 cells $/ \mathrm{mm}^{3}$ with $80 \%$ granulocytes, hemoglobin of $12.3 \mathrm{~g} / \mathrm{dL}$, and platelet count of 303000/microl. Cardiac enzymes were normal. Thyroid function tests were normal. Chemistry showed mild elevation of alkaline phosphatase and GGT. Lactate dehydrogenase was $158 \mathrm{U} / \mathrm{L}$ and ESR was $23 \mathrm{~mm} / \mathrm{hr}$. Chest radiography showed enlarged cardiac silhouette and small bilateral pleural effusions. Echocardiography showed a large pericardial effusion. He underwent pericardiocentesis with removal of $800 \mathrm{~mL}$ of hemorrhagic fluid. Symptoms improved and patient was discharged home to follow up as an outpatient. Pericardial fluid analysis revealed 12,300 leukocytes with $90 \%$ monocytes, 246,000 erythrocytes, a protein of $4.7 \mathrm{~g} / \mathrm{dL}$, and $\mathrm{LDH}$ of $6,000 \mathrm{IU} / \mathrm{L}$. The fluid was cellular and cytology showed atypical lymphocytes. Many cells were strongly positive for CD 45 and B-cell antigens, CD79a, CD 20, and PAX 5. There was no significant expression of CD10, CD30, CD138, bcl-1, bcl-6, MUM-1, calretinin, or Ber-EP4. There was no significant expression for Epstein-Barr virus (EBV). Later, he developed a purpuric rash over the extremities. Viral serologies for HIV, HCV, HHV-8, 


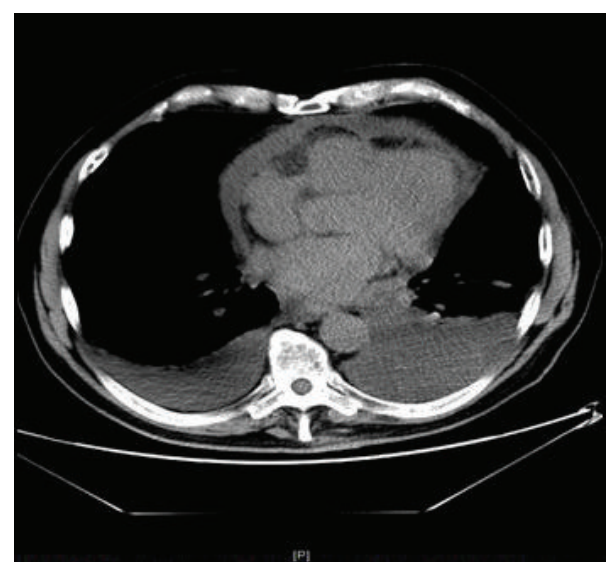

Figure 1: CT scan of chest with Pleuropericardial effusion. CT scan showing large Pleuropericardial effusion.

Lyme disease, and EBV were negative. CRP was $4.8 \mathrm{mg} / \mathrm{dL}$, but workup for SLE, rheumatoid arthritis, Sjogren's syndrome, MCTD, Wegener's granulomatosis, antiphospholipid syndrome, and paraproteinemia was negative.

A month later CT chest was done as outpatient for recurrence of symptoms.

(Figure 1) It showed recurrent small pericardial effusion and a large left-sided pleural effusion. Pleural fluid was drained. It was hemorrhagic and analysis revealed $6800 / \mathrm{mm}^{3}$ leukocytes, $110,000 / \mathrm{mm}^{3}$ erythrocytes, LDH of $1635 \mathrm{IU} / \mathrm{L}$, and amylase of $39 \mathrm{IU} / \mathrm{L}$. Fluid culture was negative. $\mathrm{He}$ underwent thoracocentesis and drainage of 2.5 liters of blood tinged fluid that showed LDH $1635 \mathrm{IU} / \mathrm{L}$, Amylase $39 \mathrm{IU} / \mathrm{L}$, RBC $110000 / \mathrm{mm}^{3}$, and WBC $6800 / \mathrm{mm}^{3}$. Cytology revealed lymphocytic effusion with atypical cells; flow cytometry was inconclusive. Gram stain; bacterial, acid fast, and mycology cultures were all negative.

Three weeks later he presented to the ER with shortness of breath, further weight loss, and worsening malaise. Chest $\mathrm{X}$-ray showed reaccumulation of large left pleural effusion and small right pleural effusion. An unchanged pericardial effusion was again noted. Due to the recurrence of pleural effusion and uncertainty of diagnosis, VATS was done with the intention to drain pleural fluid and for lymph node, pleural, and lung biopsy. After drainage of 2.5 liters of bloody fluid, talc pleurodesis was performed. Lymph node and lung biopsies were negative. Pleural fluid cytology showed atypical large cells with irregular nuclei, vesicular chromatin, and scant to moderate cytoplasm. See Figure 2; immunohistochemical stains were positive for CD-20, CD-10, BCL-2, and kappa restriction and showed a high proliferation index. There was no significant expression of BCL-1 and BCL-6. MIB-1 was expressed in the majority of the cells. The pleural adhesions showed clusters of large necrotic tumour cells and were positive for CD-20. Pathology report was in favour of diffuse large B-cell lymphoma (DLBCL).

Further imaging studies including CT abdomen/pelvis and whole body PET scan did not reveal any lymphadenopathy, organomegaly, or extra cavitary malignancy. Bone marrow biopsy was normal. Final diagnosis was HHV8-unrelated
HIV negative primary effusion lymphoma PEL-like lymphoma. Since the patient was CD 20 positive, he was offered chemotherapy with Rituximab, but he declined treatment.

$\mathrm{He}$ was monitored very closely for any recurrence of symptoms or relapse of malignancy. A PET scan was repeated a year afterwards and did not show any evidence of disease recurrence. The disease remains in complete remission till date.

\section{Discussion}

Primary effusion lymphoma (PEL) is the least common of the AIDS-related lymphomas, accounting for less than 1 to 4 percent of AIDS-related NHL $[1,2]$. It is a B-cell neoplastic process triggered by infection of the tumor clone by human herpesvirus type-8/Kaposi's sarcoma-associated herpesvirus (HHV-8/KSHV). First described in 1996 in HIV infected individuals who were coinfected with Kaposi's sarcomaassociated herpesvirus (KSHV) or $\mathrm{HHV}-8$ virus, it was included as a separate entity in WHO classification of tumors of hematopoietic and lymphoid tissue in the year 2001. PEL is characterized by liquid growth in fluid-filled body spaces, most commonly occurring in HIV patients $[3,4]$. During its entire clinical course, the lymphoma tends to remain localized to the serous body cavities with no formation of solid tumor masses. Recently, there have been a few case reports of a solid variant of PEL as well. Historically, PEL was seen in AIDS patients but recently cases have been reported in other immunosuppressive conditions like solid organ transplants $[5,6]$ and Hepatitis C infected individuals. Therefore, the epidemiology of PEL points towards a close link with the underlying host immunodeficiency. Unlike HIV and Hepatitis C, HHV-8 has a universal association with PEL. This led to its recognition as an independent lymphoma category by the World Health Organization classification system of hematologic neoplasms in 2001.

The precise B-cell subset from which these cells are derived and the biological mechanisms responsible for its unusual growth pattern (limited to body cavities) are uncertain. It has been suggested that the cells represent a preterminal stage of B-cell differentiation [7]. However, others suggest that the development of PEL is not restricted to one stage of B-cell differentiation and may represent transformation of B-cells at different stages of ontogeny [8]. Recently, Notch1, a member of a transmembrane signal transduction family, was found to be strongly expressed in PEL cell lines as well as in a majority of PEL tumors, raising the possibility that Notchl may be a downstream effector in HHV-8-mediated lymphomagenesis [9].

A search of the English literature was done through PubMed and Google Scholar using the words "PEL lymphoma," "body cavity lymphomas," and "HHV-8-unrelated PEL-like lymphomas." The search was focused on articles, reviews, and case reports published between January 1990 and September 2013. Till date, around 50 cases of HHV8-unrelated PEL-like lymphoma have been reported upon review of the literature. HIV status of seven patients was not described. All other cases were HIV negative. 10 patients 
TABLE 1: HHV-8 negative, HIV, EBV, and Hep C negative PEL-like lymphomas reported.

\begin{tabular}{|c|c|c|c|c|c|}
\hline Reference & Age/sex & Site & Immunophenotyping & Therapy & Outcome \\
\hline Terasaki et al. [15] & $99 / \mathrm{F}$ & Pleural, pericardium & $\begin{array}{l}\text { CD19, CD20, CD5, } \\
\text { CD25, IgM, IgD }\end{array}$ & Drainage & Alive at 16 months \\
\hline Wang et al. [16] & $79 / \mathrm{M}$ & Pleural & $\begin{array}{c}\text { CD 45, CD20, CD79a, } \\
\text { bcl-2, bcl-6, MUM1 }\end{array}$ & Pleurodesis & Alive at 55 months \\
\hline Terasaki et al. [15] & $85 / \mathrm{M}$ & Pleural, pericardium & $\mathrm{CD} 20$ & None & Alive at 11 months \\
\hline Inoue et al. [17] & $67 / \mathrm{F}$ & Pericardium & CD20, CD79a & $\begin{array}{l}\text { CHOP, MEPP, and } \\
\text { DEVIC }\end{array}$ & Expired in 16 months \\
\hline Kagoya et al. [18] & $74 / \mathrm{M}$ & Pericardium & $\mathrm{CD} 20$ & RCHOP & Expired in 7 months \\
\hline Takahashi et al. [19] & $73 / \mathrm{M}$ & $\begin{array}{l}\text { Pleural, pericardium, } \\
\text { and peritoneum }\end{array}$ & $\mathrm{CD} 20$ & $\mathrm{CHOP}$ & Alive at 12 months \\
\hline Terasaki et al. [20] & $68 / \mathrm{M}$ & Pleural & CD20, CD79a & RCHOP & Alive at 22 months \\
\hline Fujisawa et al. [21] & $69 / \mathrm{M}$ & Pleural, pericardium & $\begin{array}{l}\text { CD19, CD20, CD5, } \\
\text { bcl2, Cyclin D1 }\end{array}$ & THP-COP & Expired in 5 months \\
\hline Youngster et al. [22] & $88 / \mathrm{M}$ & Pleural & $\begin{array}{c}\text { CD20, CD30, CD79a, } \\
\text { CD } 45\end{array}$ & $\mathrm{RCHOP}$ & Alive at 11 months \\
\hline Hermine et al. [11] & $52 / \mathrm{F}$ & Pleural, pericardium & $\begin{array}{l}\text { CD19, CD20, CD22, } \\
\text { CD45, HLA-DR }\end{array}$ & Not mentioned & Not mentioned \\
\hline Ohshima et al. [14] & $75 / \mathrm{M}$ & Pleural & $\begin{array}{l}\text { CD19, CD20, } \\
\text { HLA-DR }\end{array}$ & $\mathrm{CHOP}$ & Expired in 15 months \\
\hline Ohshima et al. ${ }^{*}[14]$ & $76 / \mathrm{M}$ & Pleural & $\begin{array}{c}\text { CD19, CD20, CD10, } \\
\text { HLA-DR }\end{array}$ & None & Alive at 6 months \\
\hline Ohshima et al. ${ }^{*}[14]$ & $32 / \mathrm{F}$ & Peritoneum & $\begin{array}{l}\text { CD10, CD19, CD20, } \\
\text { HLA-DR }\end{array}$ & CHOP and PBSCT & Alive at 13 months \\
\hline Ohshima et al. ${ }^{*}[14]$ & $81 / \mathrm{M}$ & Pleural & $\begin{array}{l}\text { CD19, CD20, CD10, } \\
\text { CD5, HLA-DR }\end{array}$ & None & Alive at 2 months \\
\hline Shimazaki et al. [23] & $90 / \mathrm{F}$ & $\begin{array}{l}\text { Pleural, pericardium, } \\
\text { and peritoneum }\end{array}$ & CD20, CD79a, BCL-2 & None & Expired in five months \\
\hline Inoue et al. [24] & $70 / \mathrm{F}$ & Pleural, pericardium & $\begin{array}{l}\text { CD19, CD20, CD22, } \\
\text { CD24, CD8, CD10, } \\
\text { CD38, HLA DR }\end{array}$ & $\begin{array}{l}\text { CHOP and } \\
\text { sobuzoxane }\end{array}$ & Alive at 30 months \\
\hline Fujiwara et al. [25] & $75 / \mathrm{F}$ & Pericardium & CD20, CD79a & $\mathrm{CHOP}$ & Alive at 36 months \\
\hline Nemr et al. ${ }^{*}[26]$ & $92 / \mathrm{F}$ & Pleural & CD20, CD45, BCL-2 & None & Expired in 2 months \\
\hline Nakamura et al. [27] & $51 / \mathrm{M}$ & Scrotum & $\begin{array}{c}\mathrm{CD} 45, \mathrm{CD} 19, \mathrm{CD} 20, \\
\mathrm{CD} 79 \mathrm{a}\end{array}$ & $\begin{array}{c}\text { Carboplatin, } \\
\text { etoposide, } \\
\text { mitoxantrone, } \\
\text { prednisone, and RT }\end{array}$ & Alive at 8 months \\
\hline Saini et al. [28] & $87 / \mathrm{F}$ & Pleural & $\begin{array}{l}\text { CD19, CD45, CD20, } \\
\text { CD79a }\end{array}$ & Pleurodesis & Alive at 21 months \\
\hline Saini et al. [28] & $82 / \mathrm{F}$ & Pleural & $\begin{array}{l}\text { CD20, bcl6, MUM1, } \\
\text { PAX } 5\end{array}$ & Pleural drainage & Expired in 13 months \\
\hline Matsumoto et al. [29] & $90 / \mathrm{M}$ & Pleural & $\mathrm{CD} 19, \mathrm{CD} 20, \mathrm{CD} 30$ & $\mathrm{R}+\mathrm{THP}-\mathrm{COP}$ & Alive at 38 months \\
\hline Matsumoto et al. [29] & $87 / \mathrm{F}$ & Pleural & CD20, CD30 & Rituximab & Alive at 32 months \\
\hline Our patient & $76 / M$ & Pleural/pericardium & $\begin{array}{c}C D-20, C D-10 \\
B C L-2, M I B 1\end{array}$ & None & Alive at 14 months \\
\hline
\end{tabular}

* Status of Hepatitis C is not described.

Currently, there is no standard chemotherapeutic regimen for its treatment. When employed, chemotherapy has largely been based on CHOP regimen.

were EBV positive and 7 were Hepatitis $C$ positive. All of the Hepatitis C positive patients had peritoneal involvement that manifested as lymphomatous ascites. Twenty four patients (including ours) were negative for all three of the HIV, EBV, and Hepatitis $\mathrm{C}$ serology. In this review, we are presenting the clinical characteristics, therapy, and outcome of this distinct group in a tabular way (Table 1 ).
There have been few reports of PEL-like process in patients without HIV or HHV-8 infection. This particular clinical entity has now been labeled as HHV-unrelated PELlike lymphoma $[10,11]$. It also presents as lymphomatous effusion in peritoneal, pleural, and pericardial cavities. Here, we reported a case of PEL-like lymphoma, which is HIV and HHV-8 unrelated. The etiology of PEL-like lymphoma 


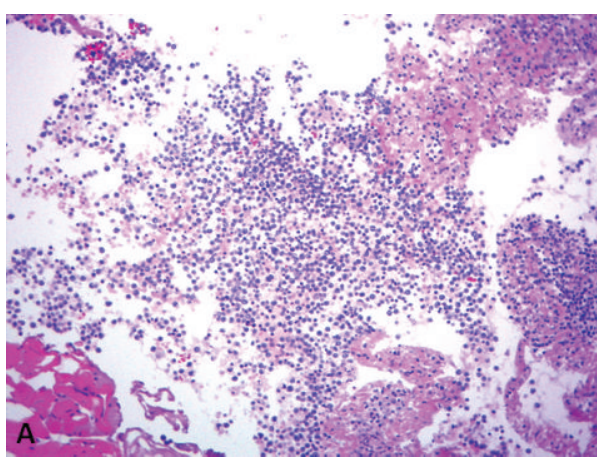

(a)

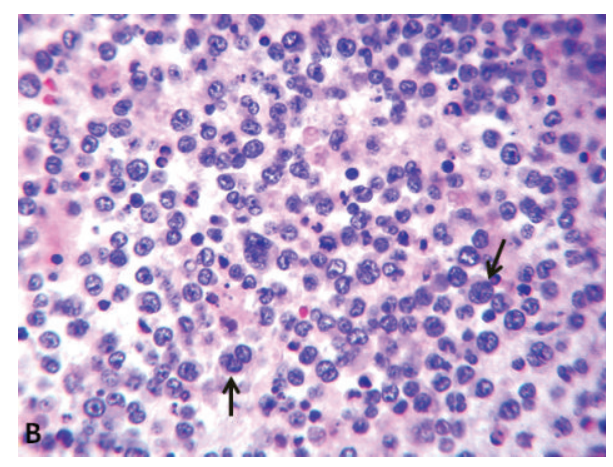

(b)

Figure 2: Pathology with H and E stain. Diffuse large B-cell lymphoma (DLBCL), pleural cavity (H\&E, (a) 100x, (b) 400x). Aggregates of large atypical lymphocytes with irregular nuclei having uneven chromatin and small to large nucleoli are evident in a necrotic background. Some cells show multilobulated nuclei (arrows). Mitosis and apoptotic bodies are conspicuous.

unrelated to HHV-8 is far less clear although it may involve infection by Hepatitis C, EBV, liver cirrhosis, and iatrogenic immunodeficiency. HCV infection, in particular, has been suggested as a possible pathogen, given that it was found in approximately $30 \%$ to $40 \%$ patients. HCV is believed to induce persistent antigenic stimulation that results in Bcell clonal expansion. Most HCV-associated diseases demonstrated peritoneal involvement and HCV-RNA has also been found in ascitic fluid [12]. EBV was also found in some patients with HHV-8-unrelated PEL-like lymphoma but its presence is not necessary for its development. A review of the literature suggests that rate of association with $\mathrm{HCV}$ and EBV was $42 \%$ and $19.4 \%$, respectively, and the most involved sites were the peritoneum and pleura; pericardial involvement was least common. However, in the majority of patients with HHV-8-unrelated PEL-like lymphoma, as in our patient, no known pathogens such as HIV, EBV, HCV, or iatrogenic immunodeficiency were identified. The only common finding in cases of PEL-like lymphoma that we came across in the published literature is that most of the patients were elderly, with a median age older than 60 years, in contrast to a median age of 44 years in PEL [13]. As it is well known that immune function decreases in geriatric populations, advanced age may be the primary reason for immunodeficiency in HHV8-unrelated PEL-like lymphoma. It has also been postulated that multistep genomic abnormalities like c-myc amplification might be involved in the development of HIV-negative, HHV8-unrelated PEL-like lymphoma [14].

\section{Conclusions}

PEL-like lymphoma can occur in people without well-defined immunodeficiency states. If detected early, it is potentially curable. Although immune dysregulation seems to play a causal role in most cases, yet absence of immunosuppression and HCV or EBV infections in our patient emphasizes that pathogenesis of PEL or HHV8-unrelated PEL-like lymphoma largely remains unexplored. Reporting of further cases might help better understand the underlying disease mechanisms and may help devise a standard treatment approach.

\section{Conflict of Interests}

The authors declare that they have no conflict of interests regarding the publication of this paper.

\section{References}

[1] C. Simonelli, M. Spina, R. Cinelli et al., "Clinical features and outcome of primary effusion lymphoma in HIV-infected patients: A single-institution study," Journal of Clinical Oncology, vol. 21, no. 21, pp. 3948-3954, 2003.

[2] S. M. Mbulaiteye, R. J. Biggar, J. J. Goedert, and E. A. Engels, "Pleural and peritoneal lymphoma among people with AIDS in the United States," Journal of Acquired Immune Deficiency Syndromes, vol. 29, no. 4, pp. 418-421, 2002.

[3] E. Cesarman, Y. Chang, P. S. Moore, J. W. Said, and D. M. Knowles, "Kaposi's sarcoma-associated herpesvirus-like DNA sequences in AIDS- related body-cavity-based lymphomas," The New England Journal of Medicine, vol. 332, no. 18, pp. 1186-1191, 1995.

[4] A. Carbone, A. Gloghini, E. Vaccher et al., "Kaposi's sarcomaassociated herpesvirus DNA sequences in AIDS-related and AIDS-unrelated lymphomatous effusions," British Journal of Haematology, vol. 94, no. 3, pp. 533-543, 1996.

[5] G. Dotti, R. Fiocchi, T. Motta et al., "Primary effusion lymphoma after heart transplantation: a new entity associated with human herpesvirus-8," Leukemia, vol. 13, no. 5, pp. 664-670, 1999.

[6] N. C. V. Melo, M. M. Sales, A. N. C. Santana, E. C. Costalonga, A. B. Pedreira, and L. E. Ianhez, "Pleural primary effusion lymphoma in a renal transplant recipient," American Journal of Transplantation, vol. 8, no. 4, pp. 906-907, 2008.

[7] G. Gaidano, A. Gloghini, V. Gattei et al., "Association of Kaposi’s sarcoma-associated herpesvirus-positive primary effusion lymphoma with expression of the CD138/syndecan-1 antigen," Blood, vol. 90, no. 12, pp. 4894-4900, 1997.

[8] A. Matolcsy, R. G. Nádor, E. Cesarman, and D. M. Knowles, "Immunoglobulin $\mathrm{V}(\mathrm{H})$ gene mutational analysis suggests that primary effusion lymphomas derive from different stages of B cell maturation," American Journal of Pathology, vol. 153, no. 5, pp. 1609-1614, 1998. 
[9] H.-Y. Wang, F. S. Fuda, W. Chen, and N. J. Karandikar, "Notch1 in primary effusion lymphoma: a clinicopathological study," Modern Pathology, vol. 23, no. 6, pp. 773-780, 2010.

[10] A. Carbone and A. Gloghini, "PEL and HHV8-unrelated effusion lymphomas: classification and diagnosis," Cancer, vol. 114, no. 4, pp. 225-227, 2008.

[11] O. Hermine, M. Michel, A. Buzyn-Veil et al., "Body-cavitybased lymphoma in an HIV-seronegative patient without Kaposi's sarcoma-associated herpesvirus-like DNA sequences," The New England Journal of Medicine, vol. 334, no. 4, pp. 272273, 1996.

[12] Y. Kobayashi, Y. Kamitsuji, J. Kuroda et al., "Comparison of human herpes virus 8 related primary effusion lymphoma with human herpes virus 8 unrelated primary effusion lymphomalike lymphoma on the basis of HIV: Report of 2 cases and review of 212 cases in the literature," Acta Haematologica, vol. 117, no. 3 , pp. 132-144, 2007.

[13] C. Adiguzel, S. U. Bozkurt, I. Kaygusuz, A. Uzay, T. Tecimer, and M. Bayik, "Human herpes virus 8-unrelated primary effusion lymphoma-like lymphoma: report of a rare case and review of the literature," APMIS, vol. 117, no. 3, pp. 222-229, 2009.

[14] K. Ohshima, M. Ishiguro, S. Yamasaki et al., "Chromosomal and comparative genomic analyses of HHV-8-negative primary effusion lymphoma in five HIV-negative Japanese patients," Leukemia and Lymphoma, vol. 43, no. 3, pp. 595-601, 2002.

[15] Y. Terasaki, H. Yamamoto, H. Kiyokawa et al., "Disappearance of malignant cells by effusion drainage alone in two patients with HHV-8-unrelated HIV-negative primary effusion lymphoma-like lymphoma," International Journal of Hematology, vol. 94, no. 3, pp. 279-284, 2011.

[16] T. Wang, V. E. Nava, G. P. Schechter, J. H. Lichy, and M.-L. Liu, "Human herpes virus 8-unrelated primary effusion lymphomalike lymphoma: a patient successfully treated with pleurodesis," Journal of Clinical Oncology, vol. 29, no. 29, pp. e747-e750, 2011.

[17] S. Inoue, T. Miyamoto, T. Yoshino, I. Yamadori, Y. Hagari, and O. Yamamoto, "Primary effusion lymphoma with skin involvement," Journal of Clinical Pathology, vol. 59, no. 11, pp. 1221-1222, 2006.

[18] Y. Kagoya, T. Takahashi, T. Yoshimoto et al., "Recurrent pericardial effusion after treatment for primary effusion lymphomalike lymphoma: an autopsied case," Annals of Hematology, vol. 90, no. 2, pp. 219-220, 2011.

[19] T. Takahashi, A. Hangaishi, G. Yamamoto, M. Ichikawa, Y. Imai, and M. Kurokawa, "HIV-negative, HHV-8-unrelated primary effusion lymphoma-like lymphoma: report of two cases," American Journal of Hematology, vol. 85, no. 1, pp. 85-87, 2010.

[20] Y. Terasaki, H. Okumura, K. Saito et al., "HHV-8/KSHVnegative and CD20-positive primary effusion lymphoma successfully treated by pleural drainage followed by chemotherapy containing rituximab," Internal Medicine, vol. 47, no. 24, pp. 2175-2178, 2008.

[21] S. Fujisawa, F. Tanioka, T. Matsuoka, and T. Ozawa, "CD5+ diffuse large B-cell lymphoma with c-myc/IgH rearrangement presenting as primary effusion lymphoma," International Journal of Hematology, vol. 81, no. 4, pp. 315-318, 2005.

[22] I. Youngster, E. Vaisben, H. Cohen, and F. Nassar, "An unusual cause of pleural effusion," Age and Ageing, vol. 35, no. 1, pp. 9496, 2006.

[23] M. Shimazaki, M. Fujita, K. Tsukamoto et al., "An unusual case of primary effusion lymphoma in a HIV-negative patient not pathogenetically associated with HHV8," European Journal of Haematology, vol. 71, no. 1, pp. 62-67, 2003.
[24] Y. Inoue, K. Tsukasaki, K. Nagai, H. Soda, and M. Tomonaga, "Durable remission by sobuzoxane in an HIV-seronegative patient with human herpesvirus 8-negative primary effusion lymphoma," International Journal of Hematology, vol. 79, no. 3, pp. 271-275, 2004.

[25] T. Fujiwara, R. Ichinohasama, I. Miura et al., "Primary effusion lymphoma of the pericardial cavity carrying $\mathrm{t}(1 ; 22)(\mathrm{q} 21 ; \mathrm{q} 11)$ and t(14;17)(q32;q23)," Cancer Genetics and Cytogenetics, vol. 156, no. 1, pp. 49-53, 2005.

[26] S. Nemr, M. H. Mayor-Modesto, S. Schwartz, and E. M. Summerhill, "A 92-year-old woman with recurrent pleural effusions," Chest, vol. 134, no. 1, pp. 196-199, 2008.

[27] Y. Nakamura, F. Tajima, H. Omura, K. Ishiga, T. Kawatani, and Y. Murawaki, "Primary effusion lymphoma of the left scrotum," Internal Medicine, vol. 42, no. 4, pp. 351-353, 2003.

[28] N. Saini, E. P. Hochberg, E. A. Linden, S. Jha, H. K. Grohs, and A. R. Sohani, "HHV8-negative primary effusion lymphoma of B-cell lineage: two cases and a comprehensive review of the literature," Case Reports in Oncological Medicine, vol. 2013, Article ID 292301, 12 pages, 2013.

[29] Y. Matsumoto, K. Nomura, K. Ueda et al., "Human herpesvirus 8-negative malignant effusion lymphoma: a distinct clinical entity and successful treatment with rituximab," Leukemia and Lymphoma, vol. 46, no. 3, pp. 415-419, 2005. 


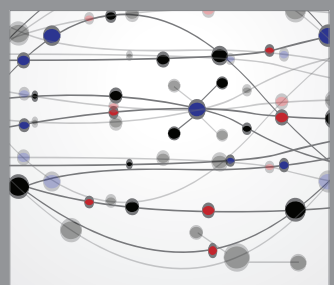

The Scientific World Journal
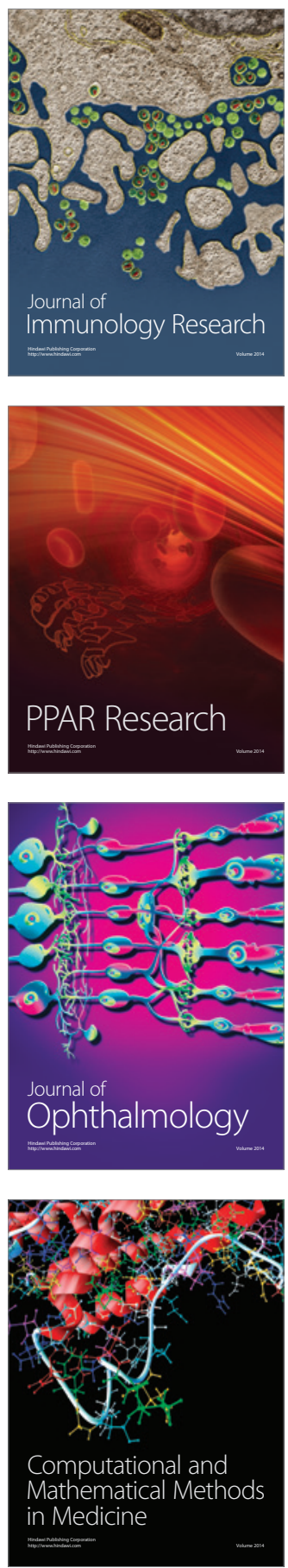

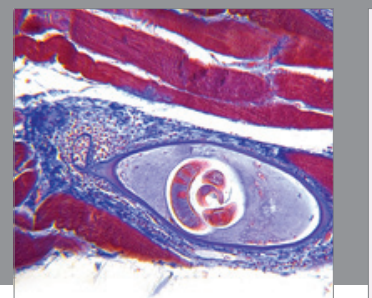

Gastroenterology

Research and Practice
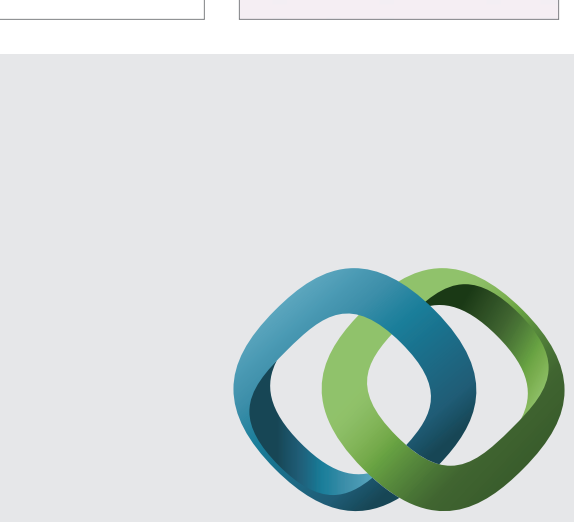

\section{Hindawi}

Submit your manuscripts at

http://www.hindawi.com
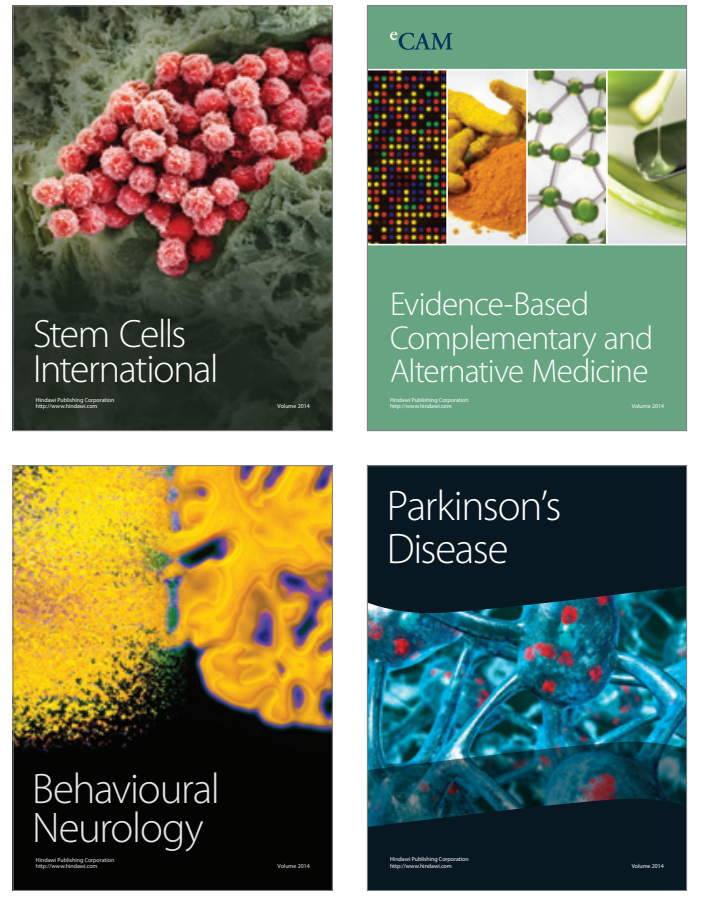
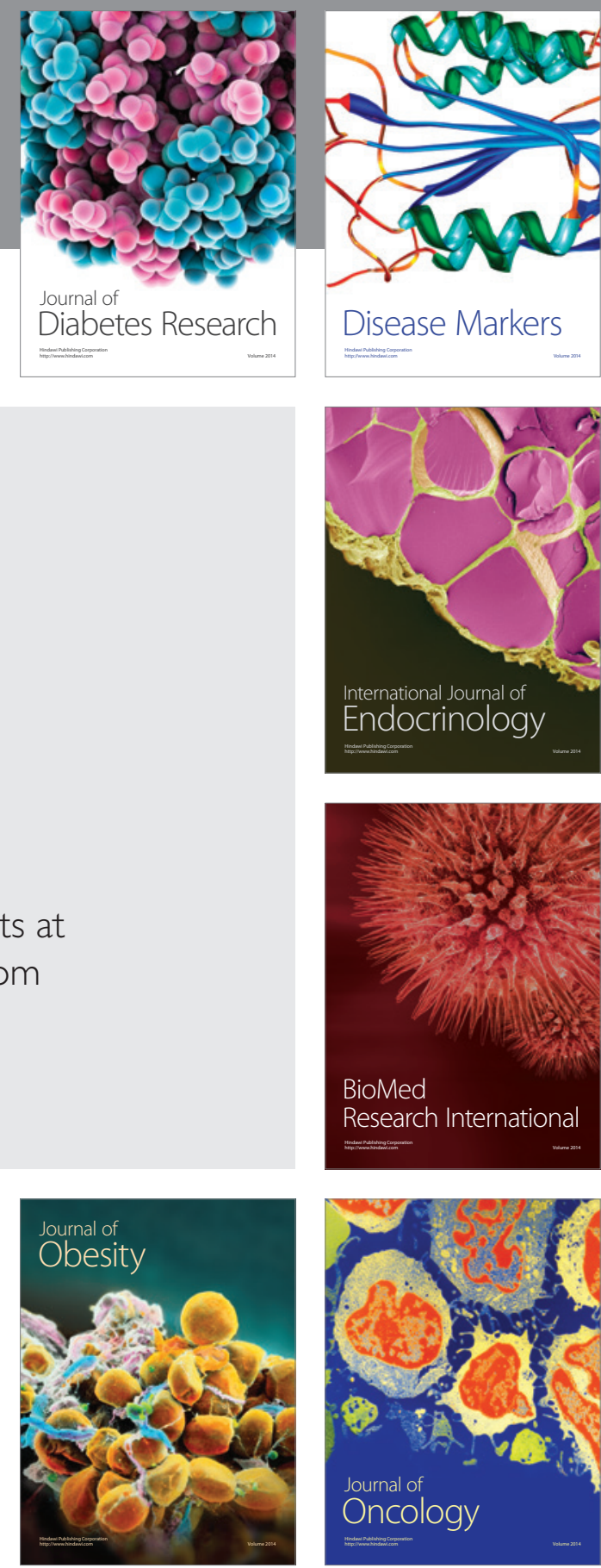

Disease Markers
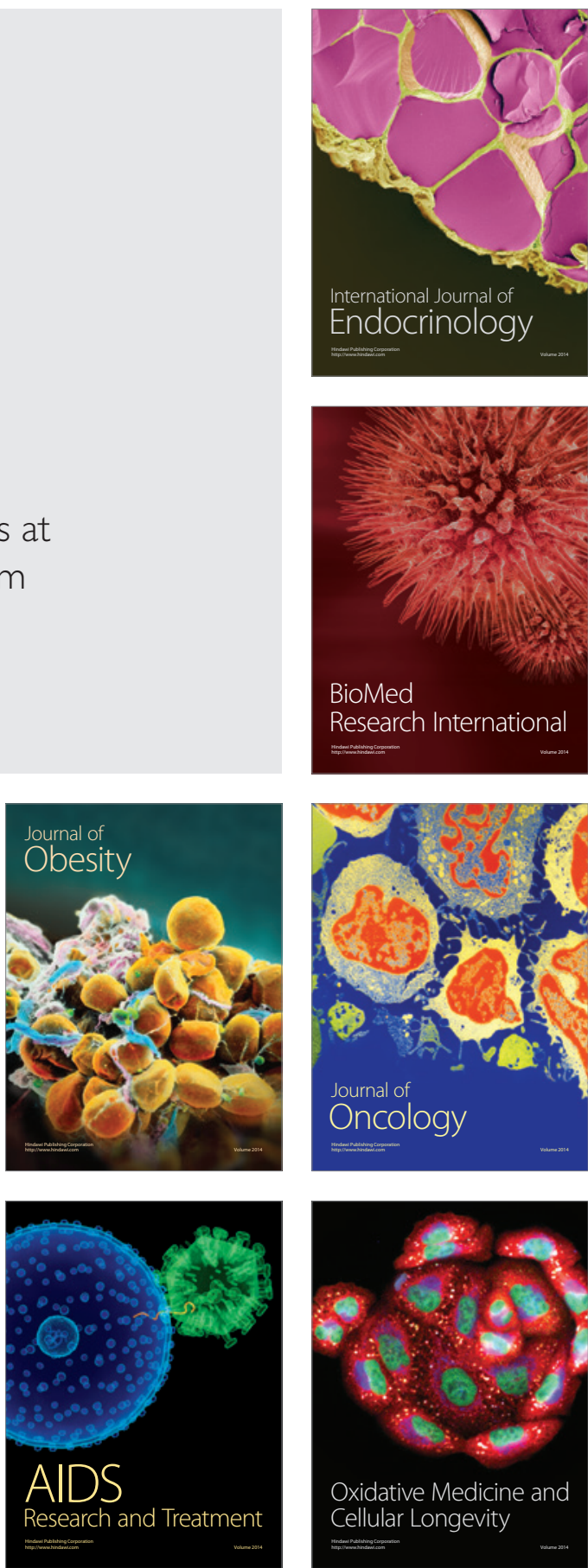